\title{
Recent patents in proteomics
}

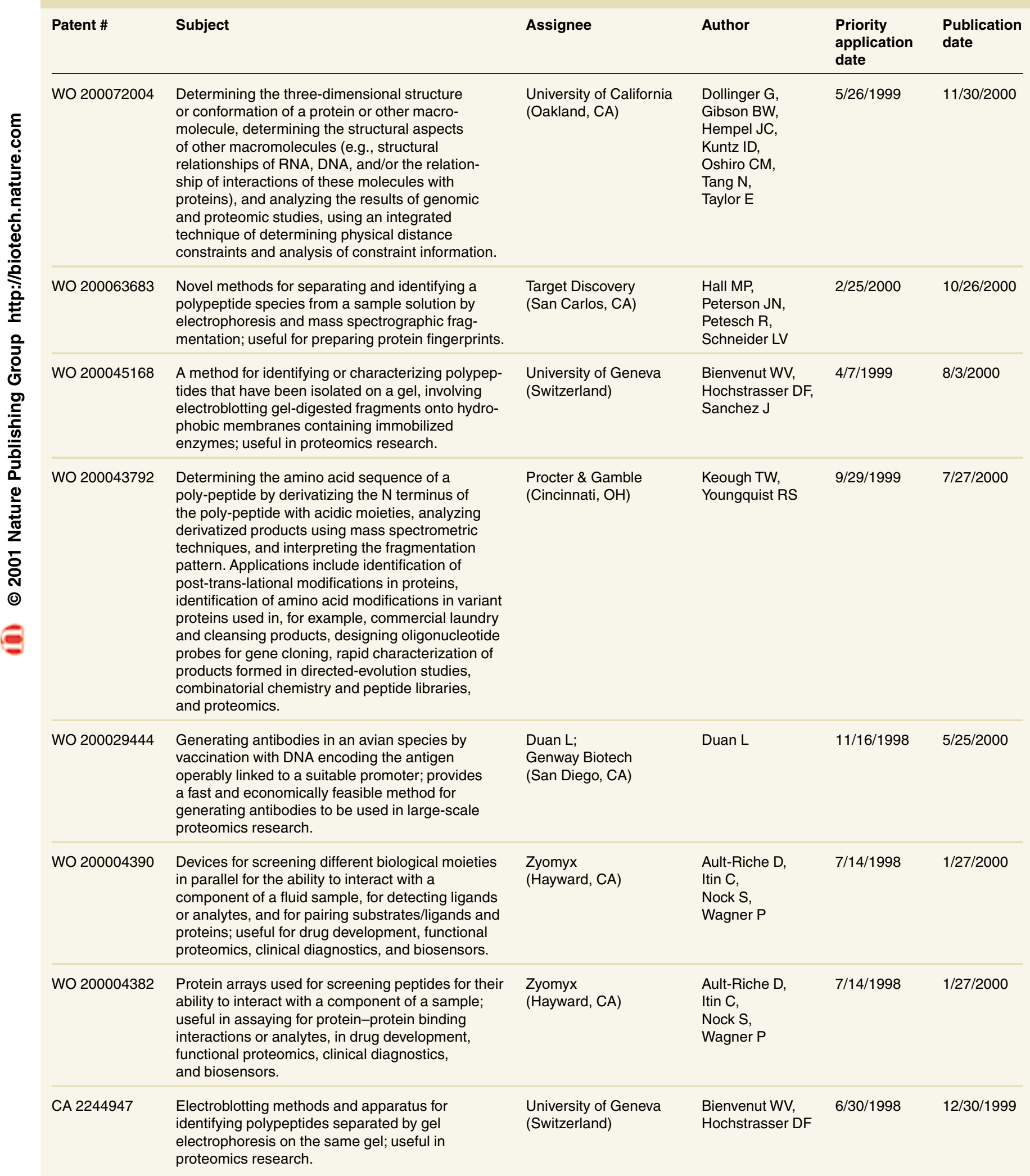

Source: Derwent Information, Alexandria, VA. The status of each application is slightly different from country to country. For further details, contact Derwent Information, 1725 Duke Street, Suite 250, Alexandria, VA 22314. Tel: 1 (800) DERWENT (info@derwent.com). 